\title{
PENJADWALAN DISTRIBUSI BBM UNTUK SELF PROPELLED OIL BARGE (SPOB) BERBASIS METODE ANALYTICAL HIERARCHY PROCESS (AHP)
}

\author{
Pitarsono Yulihartanto*1, Nur Aini Masruroh ${ }^{1,2}$, Joko Waluyo ${ }^{1,2}$ \\ ${ }^{1}$ Magister Teknik Sistem, Fakultas Teknik, Universitas Gadjah Mada, \\ Jl. Teknika Utara, Yogyakarta, Indonesia 55281 \\ ${ }^{2}$ Departemen Teknik Mesin dan Teknik Industri, Fakultas Teknik, Universitas Gadjah Mada, \\ Jl. Grafika No.2, Yogyakarta, Indonesia 55281
}

\begin{abstract}
Abstrak
Pelaksanaan kegiatan operasional di area offshore pada perusahaan eksplorasi dan eksploitasi minyak dan gas bumi membutuhkan bahan bakar yang cukup banyak. Bahan bakar ini sebagian besar digunakan untuk mobilisasi berbagai jenis kapal sebagai fuel object dan operasional harian proses produksi. Terdapat beberapa kriteria umum yang menjadi dasar penjadwalan pengisian BBM, namun setiap koordinator berhak menyusun penjadwalan berdasarkan pengalaman dan subjektifitas masing-masing. Oleh karena itu jadwal yang disusun antar koordinator bisa sangat berbeda, agar memiliki standar yang seragam maka sangat diperlukan suatu metode yang terstruktur dengan kriteria standar dalam pengambilan keputusan penyusunan penjadwalan pengisian BBM. Penelitian ini bertujuan untuk mengetahui kriteria apa saja yang menjadi dasar pertimbangan dalam penjadwalan pengisian BBM dan mengembangkan suatu sistem agar keputusan penjadwalan yang diambil bisa terukur dan dipertanggungjawabkan dengan baik. Metode yang digunakan pada penelitian ini adalah rating approach Analytical Hierarchy Process (AHP), sedangkan pengelompokan kapal (klaster) yang akan diisi menggunakan metode hierarki agglomerative, complete linkage dengan euclidean distance. Hasil dari penelitian ini menunjukkan bahwa area kerja akan dibagi menjadi 3 klaster dengan jumlah SPOB sebanyak 3. Selanjutnya kriteria yang dijadikan dasar pertimbangan dalam pengambilan keputusan penjadwalan pengisian BBM adalah fuel remaining day fuel object, prioritas operasi, akses menuju fuel object dan jarak $S P O B$ dengan fuel object. Berdasarkan analisis implementasinya, metode penjadwalan dengan menggunakan rating approach AHP dapat memberikan jadwal yang konsisten, terukur,bisa dipertanggungjawabkan, dan sangat mudah diimplementasikan serta dapat menghindari terjadinya perbedaan penjadwalan (subjektivitas) antar koordinator.
\end{abstract}

Kata kunci: Analytical Hierarchy Process; Fuel Object; Penjadwalan; SPOB

*Penulis Korespondensi.

E-mail: pitarsono81@gmail.com

\section{Abstract}

[Fuel Distribution Scheduling For Self Propelled Oil Barge (SPOB) Based On The Hierarchy Process Analityc Method] The implementation of operational activities in the offshore area of oil and gas exploration and exploitation companies requires quite a lot of fuel. This fuel is mostly used for the mobilization of various types of ships as a fuel object and for the daily operations of the production process. There are several general criteria that form the basis for scheduling refueling, but each coordinator has the right to arrange a schedule based on their own experience and subjectivity. Therefore, the schedule prepared between the coordinators can be very different, in order to have a uniform standard, it is necessary to have a structured method with standard criteria in making decisions on the preparation of fuel filling scheduling. This study aims to find out what criteria are the basic considerations in scheduling refueling and develop a system so that scheduling decisions taken can be measured and accounted for properly. The method used in this study is the rating approach Analytical Hierarchy Process (AHP), while the grouping of ships (clusters) to be filled using the agglomerative hierarchy method, complete linkage with euclidean distance. The results of this study indicate that the work area will be divided into 3 clusters with the number of SPOB as much as 3. Furthermore, the criteria that are used as the basis for consideration in making decisions about fuel filling scheduling are fuel remaining day fuel object, operating priority, access to fuel object and distance between $S P O B$ and fuel. objects. Based on the implementation analysis, the 
scheduling method using the AHP rating approach can provide a schedule that is consistent, measurable, accountable, and very easy to implement and can avoid scheduling differences (subjectivity) between coordinators.

Keywords: Analytical Hierarchy Process; Fuel Object; Scheduling; SPOB

\section{Pendahuluan}

PT X merupakan salah satu perusahaan yang bergerak dalam bidang eksplorasi maupun eksploitasi sumber daya energi, khususnya industri minyak dan gas bumi. Area kerjanya sebagian besar terletak di perairan area delta (swamp) dan area lepas pantai (off shore). Untuk menunjang operasi utama seperti kegiatan pengeboran di lepas pantai diperlukan peranan dari kapal-kapal lain sebagai pendukung dalam proses pengerjaannya. Proses supporting ini terdiri dari berbagai jenis kapal (vessel), sesuai dengan fungsi pelayanan masing-masing (Guritno, 2018).

Berdasarkan data pada bulan November 2020 terdapat 97 fuel object yang berada di area kerja perusahaan, terdiri dari beberapa jenis yaitu 15 kapal well intervention, 58 jenis kapal Landing Craft Tank (LCT) dan Tug Boat (TB) lainnya, 14 crane barge konstruksi, dan 2 kapal untuk keperluan rig pengeboran. Di samping itu juga terdapat 8 site shore tank di area kerja tersebut. Dengan jumlah fuel object yang beragam, banyak dan mobile, tentunya diperlukan bahan bakar yang tidak sedikit dan harus selalu tersedia untuk menunjang kelancaran kegiatan operasionalnya. Proses pendistribusian dan bongkar muat BBM ini disebut dengan istilah bunker dan kegiatan refueling BBM dari kapal ke kapal yang dilakukan di tengah laut biasa disebut dengan metode ship to ship bunker (Arditiya, 2020).

Seluruh kebutuhan BBM untuk kegiatan operasional saat ini disuplai oleh supplier dari luar perusahaan dengan metode direct refueling, artinya supplier akan mengirimkan BBM langsung dari fuel depot menuju intermediate floating storage, selanjutnya dengan menggunakan self propelled oil barge (SPOB) BBM akan dikirimkan menuju lokasi fuel object yang direpresentasikan dalam 35 titik lokasi. Dalam proses pendistribusian BBM ini digunakan 3 buah kapal SPOB. SPOB adalah jenis kapal pengangkut minyak yang mempunyai tenaga penggerak sendiri dengan konstuksi lambung datar (barge) (Arditiya, 2020). Saat kondisi stok BBM pada SPOB akan habis maka SPOB akan mendatangi intermediate floating storage untuk melakukan refueling, dan ketika kondisi stok pada intermediate floating storage akan habis maka akan dilakukan refueling di fuel depot dan proses ini akan terus berulang. Lokasi floating storage, SPOB dan fuel object berada pada area kerja perusahaan untuk memudahkan proses monitoring dan kontrol distribusi BBM oleh departemen fuel management. Proses distribusi BBM disajikan pada Gambar 1.

Salah satu kriteria yang digunakan oleh departemen fuel management dalam penjadwalan adalah fuel remaining day, yaitu sisa hari BBM untuk kegiatan operasional pada kapal tersebut. Akan tetapi terkadang dalam pelaksanaannya terdapat kriteria lain yang mempengaruhi penjadwalan pengisian BBM seperti jenis kapal yang akan diisi, jarak, lokasi, impact jika terjadi keterlambatan pengisian, dan lain lain. Oleh karena itu dalam kondisi tertentu keputusan penjadwalan pengisian BBM antar pengambil keputusan bisa berbeda-bedan, sehingga diperlukan suatu referensi sistem yang standar dalam pengambilan keputusan untuk menentukan kriteria apa saja yang berpengaruh, sehingga mampu membuat jadwal pengisian BBM fuel object menjadi lebih terukur dan bisa dipertanggungjawabkan.

Sudah banyak penelitian yang dilakukan berhubungan dengan proses penjadwalan pengisian BBM pada transportasi maritim, salah satunya adalah oleh Gusmery dan Rachman (2013). Pada penelitian ini mereka membuat jadwal dan rute pelayanan pengisian bunker BBM MFO 380 dalam jangka waktu satu bulan untuk kapal-kapal tujuan luar negeri di Kalimantan Timur dan Kalimantan Selatan dengan metode ship to ship refueling. Dasar yang digunakan adalah Vehicle Routing Problem with Time Windows menggunakan algoritma Branch and Bound. Tujuan dari penelitian ini adalah mendapatkan rute paling optimal untuk menekan biaya operasional. Penelitian berikutnya dilakukan oleh Rodrigues dkk. (2016), mereka melakukan penyelesaian permasalahan ship routing problem with pickup and delivery and time windows untuk transportasi maritim dari perusahaaan eksplorasi minyak yang beroperasi di negara Brazil. Mereka membuat rute dan jadwal untuk

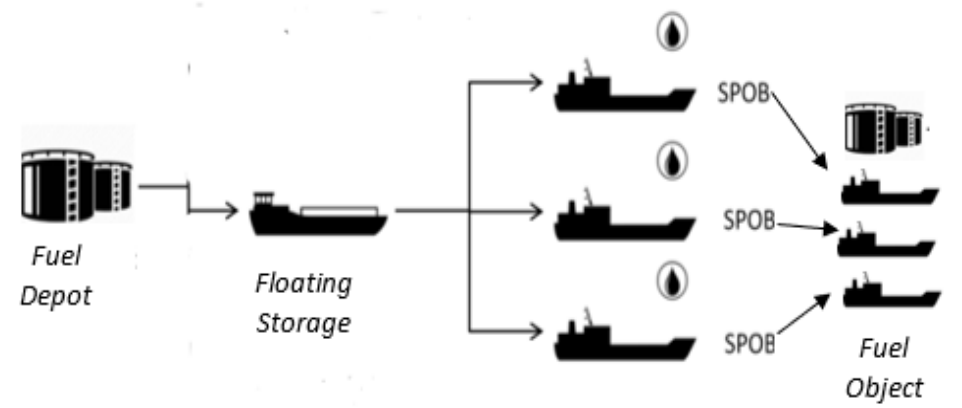

Gambar 1. Ilustrasi Proses Distribusi BBM 
kapal transportasi minyak dari offshore platforms menuju coastal terminals. Pendekatan yang digunakan adalah mixed integer programming (MIP) model dengan relax and fix and time decomposition heuristics. Tujuan dari penelitian ini adalah untuk meminimalkan fuel costs untuk kegiatan operasional kapal transportasi minyak.

Jika dilihat bahwa rata-rata penyelesaian untuk permasalahan transportasi maritim didekati dengan pendekatan vehicle routing problem, yang diselesaikan dengan metode eksak atau heuristik. Tujuan penyelesaiannya yaitu optimasi jarak untuk mendapatkan biaya paling minimal dengan variasi constrain. Akan tetapi jika dipahami secara lebih spesifik lagi, bahwa dalam kasus penjadwalan pengisian BBM fuel object di perusahaan ini tujuan utamanya adalah untuk menentukan urutan prioritas yang akan diisi dahulu dari satu set fuel object yang tersedia. Sedangkan biaya perjalanan pengisian tetap tanpa memperhatikan lokasi fuel object. Di samping itu, kondisi fuel object yang selalu berpindah-pindah tentu akan menjadi permasalahan sendiri jika dilakukan dengan pendekatan vehicle routing problem, terutama dalam perumusuan model matematisnya. Biasanya penjadwalan dibuat hanya untuk sekitar 2 sampai dengan 3 hari karena sifat objeknya yang dinamis sehingga dalam pelaksanaannya nanti dikhawatirkan akan menyulitkan pihak koordinator karena harus memodelkan secara terus menerus. Oleh karena itu diperlukan alternatif sistem pengambilan keputusan dengan metode yang lain yang lebih kompatibel dalam menyelesaikan permasalahan penjadwalan pengisian BBM di industri ekspolorasi minyak bumi.

Beberapa penelitian terdahulu telah dilakukan, terutama yang berkaitan dengan penyelesaian permasalahan suatu sistem pengambilan keputusan. Salah satu metode yang umum digunakan adalah Analytical Hierarchy Process (AHP). AHP memiliki keunggulan untuk mengatasi permasalahan kompleks dengan tipikal campuran antara permasalahan kuantitatif dan kualitatif. Karena dengan menggunakan struktur hierarki maka kompleksitas dari permasalahan tersebut akan lebih mudah untuk dipahami, selanjutnya permasalahan tersebut direpresentasikan dalam bentuk level-level untuk diatur lebih terstruktur dan sistematis sehingga akan lebih mudah untuk diselesaikan nantinya (Saaty, 1980).

Beberapa permasalahan kompleks telah banyak diselesaikan dengan menggunakan AHP sebagai tools utamanya, salah satunya adalah dengan melakukan perankingan terhadap satu set alternatif sehingga pengambilan keputusan terbaik bisa didapatkan. Seperti penelitian yang telah dilakukan oleh Dočkalíková dan Kashi (2013) yaitu menggunakan AHP dan WSA sebagai tools untuk mendapatkan calon karyawan terbaik dalam proses rekruitmen pegawai. Di samping itu Mujito, dkk (2018) juga melakukan penelitian sejenis yaitu menggunakan Analytical Hierarchy Process (AHP) dan ISO 9126 dengan tujuan untuk menghasilkan suatu sistem pendukung keputusan yang menghasilkan keluaran berupa pemeringkatan setiap calon karyawan dalam proses seleksi. Selain digunakan dalam proses rekruitmen, AHP juga bisa digunakan untuk mengevaluasi kinerja karyawan suatu perusahaan yang telah berjalan dalam kurun waktu tertentu seperti yang dilakukan oleh Yuliani (2013) dan Norddin (2015). Bahkan dalam penelitian Tseng (2018) AHP digunakan sebagai tools untuk mengidentifikasi kriteria utama yang mempengaruhi keputusan (sebagai pertimbangan) operator pelayaran terkait dengan penggunaan rute pelayaran Arktik

Dari penelitian-penelitian ini terlihat bahwa AHP memiliki potensi yang sangat baik dalam menyelesaikan permasalahan kompleks yang membutuhkan perankingan terhadap satu set alternatif yang tersedia. Jika dilihat, kasus penentuan prioritas pengisian BBM pada fuel object yang terjadi di industri ekspolorasi minyak bumi ini merupakan salah satu kasus yang bisa didekati dengan menggunakan penyelesaian perankingan AHP, artinya setiap entitas dari fuel object nantinya akan dinilai dan fuel object dengan ranking tertinggi akan terpilih sebagai prioritas utama untuk diisi BBM terlebih dahulu.

Berdasarkan studi literatur yang telah dilakukan, belum ada penelitian sejenis yang spesifik menggunakan AHP sebagai dasar untuk membuat keputusan penjadwalan pengisian BBM oleh SPOB. Lebih lanjut, mengingat fuel object yang dijadwalkan berubah-ubah setiap harinya dan jumlahnya yang banyak, maka AHP perlu dimodifikasi sehingga lebih fleksibel dan cocok diterapkan untuk sistem terbuka dalam hal ini alternatif yang dibandingkan berubahubah. Dalam penelitian ini, rating approach AHP akan digunakan. Dengan menggunakan kriteria-kriteria yang sudah dibobot yang didapat dari hasil pairwise comparison, maka proses scoring terhadap masingmasing alternatif (fuel object) bisa dilakukan dan akhirnya dapat ditentukan alternatif terbaiknya.

Dengan adanya penelitian ini diharapkan dapat diketahui kriteria apa saja yang menjadi dasar pertimbangan dalam pengambilan keputusan penjadwalan pengisian BBM pada fuel object dan didapatkannya suatu pengembangan sistem pengambilan keputusan yang terukur dan bisa dipertanggungjawabkan dalam penjadwalan pengisian BBM menggunakan metode AHP. Oleh karena itu nantinya setiap pengambil keputusan penjadwalan pengisian BBM dari departemen fuel management akan memiliki preferensi awal yang sama dalam proses pembuatan jadwal.

\section{Metode Penelitian}

Penelitian ini adalah merupakan studi kasus di industri ekspolorasi minyak bumi yang diawali dengan menentukan kriteria-kriteria yang berpengaruh terhadap pemilihan fuel object mana yang akan diisi BBM terlebih dahulu (penjadwalan berdasarkan ranking) oleh SPOB. Langkah pertama yang akan dilakukan adalah klasterisasi area untuk membagi area kerja masingmasing SPOB. Karena terdapat 3 SPOB, maka fuel 
object akan dikelompokkan menjadi 3 klaster. Langkah berikutnya adalah melakukan pembuatan struktur hierarki AHP, dimulai dengan menentukan kriteria apa saja yang mempengaruhi penjadwalan pengisian BBM, hal ini dilakukan dengan metode wawancara langsung dengan tiga orang responden dari pihak yang bertanggung jawab terhadap penjadwalan pengisian BBM fuel object dari departemen fuel management. Supaya AHP yang terbentuk dapat digunakan untuk mengevaluasi alternatif yang selalu berubah-ubah, maka setiap kriteria akan dibagi menjadi beberapa skala intensitas. Kemudian setelah mendapatkan kriteria dan intensitas untuk masing-masing kriteria, maka responden akan diminta untuk mengisi kusioner pairwise comparison pada masing masing kriteria dan intensitas. Seteleh diperoleh bobot untuk setiap kriteria dan juga bobot untuk setiap intensitas pada masingmasing kriteria, selanjutnya khusus untuk bobot intensitas pada setiap kriteria diubah ke dalam bentuk ideal. Dalam hal ini, bobot intensitas dibagi dengan bobot tertingginya. Dengan demikian, intensitas dengan bobot tertinggi akan memiliki nilai 1 . Setelah kriteria dan sub kriteria tersebut dibobot maka dilakukan penilaian (scoring) terhadap semua fuel object yang didasarkan pada bobot kriteria dan intensitas yang melekat pada masing-masing fuel object tersebut. Analisa pengambilan keputusan didasarkan pada peringkat skor untuk setiap klaster.

\subsection{Sumber Data}

Sumber data dari penelitian ini adalah data primer industri ekspolorasi minyak bumi. Responden penelitian ini adalah para pengambil keputusan (koordinator) dari departemen fuel management yang memang sudah mempunyai hak dalam pengambilan keputusan penyusunan penjadwalan pengisian BBM pada fuel object sebelumnya, sudah berpengalaman selama bertahun-tahun dan dianggap profesional dalam bidang tersebut. Total responden adalah sejumlah 3 orang. Serta data sekunder juga digunakan sebagai pelengkap dalam proses penjelasan kriteria dan subkriteria penyusun struktur hierarki AHP yang dirancang. Data sekunder berupa SOP dan data informasi bulan November 2020 mengenai posisi, status, kondisi BBM tersisa, kondisi lokasi, dan informasi lainnya yang terkait dengan masing-masing fuel object dan SPOB.

\subsection{Variabel Penelitian}

Variabel pada penelitian ini adalah satu set alternatif fuel object per area kerja yang sudah di klaster, terdiri dari beberapa jenis, yaitu: kapal LCT dan TB lainnnya, kapal operasional drilling rig, crane barge konstruksi, dan site shore tank. Adapun kriteria yang digunakan antara lain adalah: fuel remaining day, jarak kapal SPOB dan kapal yang akan diisi, jenis kapal yang akan diisi, status kapal, kondisi cuaca dan lingkungan kapal yang akan diisi, serta kriteria lain yang akan didapat saat proses wawancara dengan pihak responden.

\subsection{Analisis Data}

Analisis data pada penelitian ini diawali dengan melakukan klasterisasi 35 titik lokasi area kerja dengan metode hierarki agglomerative, complete linkage dan perhitungan jarak tiap titik menggunakan euclidean distance, sedangkan hasil klasterisasi akan ditampilkan dalam bentuk dendogram. Selanjutnya dengan menggunakan menggunakan pendekatan metode rating approach Analytical Hierarchy Process (AHP) maka proses perankingan fuel object pada masing-masing klaster bisa dilakukan. Pelaksanaannya mengikuti langkah sebagai berikut:

1. Penyusunan hierarki akan disusun kedalam 4 level, yaitu level 0 adalah tujuan, level 1 adalah kriteria, level 2 adalah subkriteria dan level 3 adalah alternatif.

2. Membuat matriks berpasangan untuk level 1. Dari matriks tersebut dapat ditentukan nilai $\lambda_{\text {maks }}$ dan melakukan pengecekan aturan konsistensi dengan menggunakan rumus:

$$
C I=\frac{\lambda_{m a k s}-n}{n-1}
$$

Di mana, CI adalah indeks konsistensi; $\lambda_{\text {maks }}$ adalah eigenvalue maksimum; dan $\mathrm{n}$ adalah orde matriks. Setelah mengetahui nilai CI, maka baru bisa ditentukan nilai $\mathrm{CR}$.

$$
C R=\frac{C I}{R I}
$$

Di mana CR adalah rasio konsistensi dan RI adalah indeks random (nilai disesuaikan dengan orde matriks). Dalam model AHP, matriks perbandingan yang dapat diterima yaitu jika nilai rasio konsistensi (CR) $\leq$ 0,1 (Ilhami, 2017).

Setelah memenuhi persyaratan konsistensi maka baru dilakukan perhitungan pembobotan untuk masing masing kriteria dan subkriteria (dengan total jumlah pembobotan adalah 1).

3. Membuat matriks berpasangan untuk intensitas rating pada masing masing leaf kriteria yang telah ditentukan dan melakukan pengecekan konsistensi matriksnya. Kemudian melakukan pembobotan (dengan total jumlah pembobotan adalah 1), selanjutnya mengubah hasil pembobotan intensitas rating tersebut dalam bentuk ideal form rating (membagi nilai bobot yang sudah dinormalisasi dengan nilai bobot tertinggi) dan selanjutnya masing-masing intensitas akan disusun secara rating sesuai dengan nilainya.

4. Melakukan proses penilaian untuk masing-masing alternatif yang disediakan dan melakukan proses perankingan.

\section{Hasil dan Pembahasan}

\subsection{Klasterisasi Lokasi Fuel Object}

Analisis cluster adalah teknik untuk mengelompokkan pengamatan yang serupa ke dalam beberapa cluster berdasarkan nilai pengamatan beberapa variabel untuk setiap individu. Analisis cluster mirip dalam konsep dengan analisis diskriminan. Keanggotaan kelompok dari sampel pengamatan 


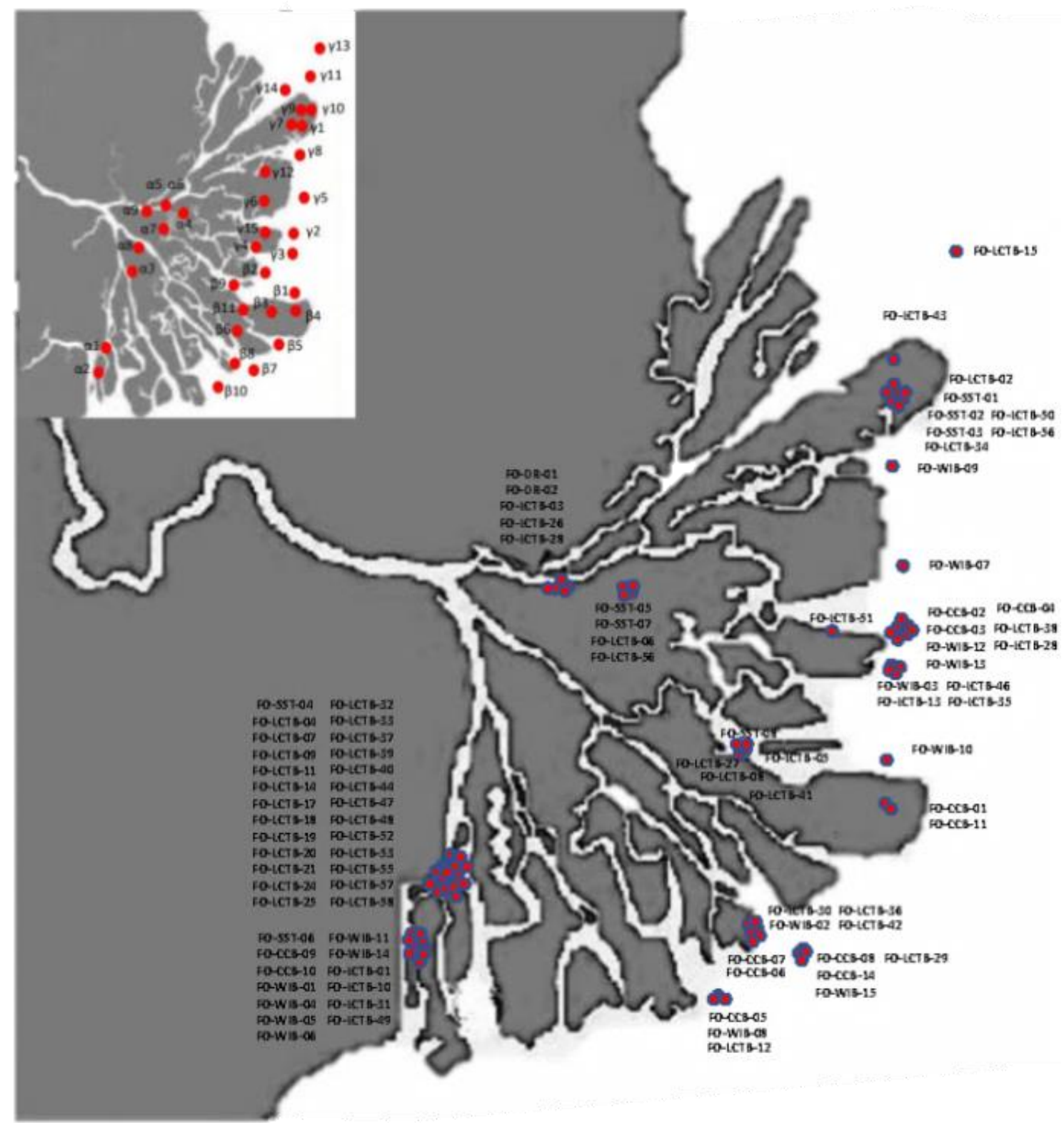

Gambar 2. Peta Sebaran Lokasi Fuel Object (sumber: olahan http://maps.google.com/)

diketahui di awal sementara tidak diketahui untuk pengamatan sebelumnya (Sinharay, 2010).

Fuel object merupakan entitas paling akhir dari proses pendistribusian BBM, BBM pada fuel object akan diisi langsung oleh SPOB. Fuel object terdiri dari dua kategori yaitu stasioner yang menetap di suatu lokasi dan dinamis yang berpindah-pindah. Berdasarkan data yang didapat dari departemen fuel management pada bulan November 2020, total fuel object berjumlah 97 yang tersebar diberbagai lokasi.

Klasifikasi fuel object dapat dibagi menjadi 4 kategori yaitu site shore tank dengan kode nama FOSST-xx, rig pengeboran dengan kode nama FO-DR-xx, barge/kapal intervensi sumur dengan kode nama FOWIB-xx, crane barge konstruksi dengan kode nama FOCCB-xx, kapal LCT dan tug boat lainnya dengan kode nama FO-LCTB-xx. Gambar 2 disajikan sebaran 97 fuel object di lokasi kerja.
Dasar dari proses klasterisasi ini menggunakan data koordinat dari masing-masing lokasi (latitude dan longitude). Tujuan dari proses klasterisasi adalah untuk menyederhanakan proses permodelan distribusi BBM, sehingga setiap SPOB nantinya akan memiliki area kerja masing-masing.

Proses klasterisasi ini dilakukan menggunakan software Minitab versi 19, dengan inputan data berupa koordinat (latitude dan longitude) untuk 35 titik lokasi yang merepresentasikan wilayah operasi perusahaan. Dengan bantuan software Minitab, klasterisasi akan dilakukan dengan metode hierarki agglomerative, complete linkage dan perhitungan jarak tiap titik menggunakan euclidean distance. Dasar proses klasterisasi dengan menggunakan metode agglomerative adalah dengan cara menggabungkan 2 entitas dengan jarak terdekat yang dianggap memiliki nilai similarity tertinggi. 


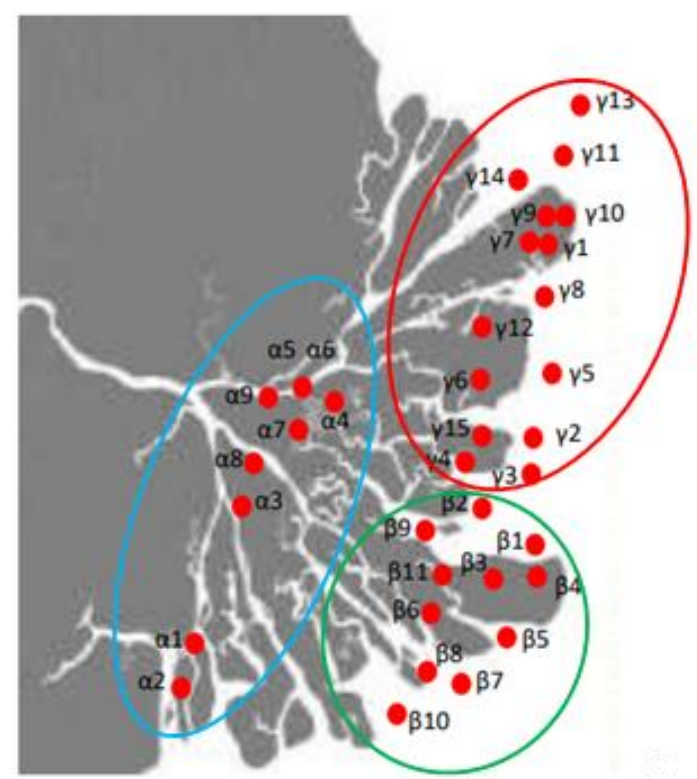

Gambar 3. Peta Hasil Proses Klasterisasi Titik Lokasi Kerja (sumber: olahan http://maps.google.com/)

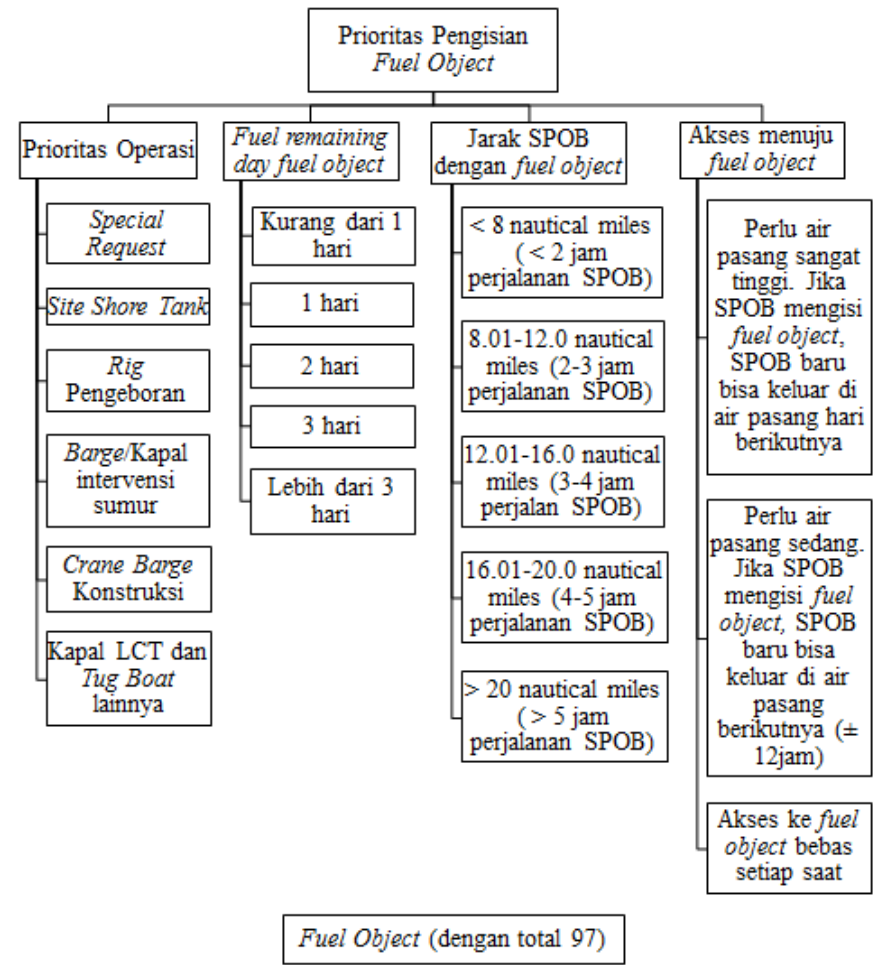

Gambar 4. Struktur Hierarki Penjadwalan Distribusi BBM Menggunakan SPOB

Proses klasterisasi ini dilakukan menggunakan software Minitab versi 19, dengan inputan data berupa koordinat (latitude dan longitude) untuk 35 titik lokasi yang merepresentasikan wilayah operasi perusahaan. Dengan bantuan software Minitab, klasterisasi akan dilakukan dengan metode hierarki agglomerative, complete linkage dan perhitungan jarak tiap titik menggunakan euclidean distance. Dasar proses klasterisasi dengan menggunakan metode agglomerative adalah dengan cara menggabungkan 2 entitas dengan jarak terdekat yang dianggap memiliki nilai similarity tertinggi. Hasil klasterisasi disajikan dalam bentuk dendogram. Dendogram ini akan menggambarkan nilai koefisien jarak dalam setiap langkah dan bagaimana cluster terbentuk (Usman, 2013).

Masing-masing fuel object telah diklasifikasikan berdasarkan klaster lokasi. Klaster 1 terdiri dari 48 fuel object yang tersebar pada lokasi $\alpha 1, \alpha 2, \alpha 4$ dan $\alpha 5$. Klaster 2 terdiri dari 21 fuel object yang tersebar pada lokasi $\beta 1, \beta 4, \beta 7, \beta 8, \beta 9$, dan $\beta 10$. Klaster 3 terdiri dari 23 fuel object yang tersebar pada lokasi $\gamma 1, \gamma 2, \gamma 3, \gamma 5$, $\gamma 8, \gamma 9, \gamma 13$, dan $\gamma 15$. Setelah didapatkan klasterisasi titik lokasi area kerja, maka bisa dihitung data jarak fuel object terhadap SPOB pada masing masing klaster. Untuk memperjelas hasil pembagian area menggunakan klasterisasi maka berikut disajikan pada Gambar 3. 
Tabel 1. Nilai Rata-Rata (Pendekatan Pembulatan) Tingkat 2 (Kriteria)

\begin{tabular}{lccccc}
\hline \multicolumn{1}{c}{ Pairwise Comparison } & $\begin{array}{c}\text { Prioritas } \\
\text { Operasi }\end{array}$ & $\begin{array}{c}\text { Fuel Remaining } \\
\text { Day Fuel Object }\end{array}$ & $\begin{array}{c}\text { Jarak SPOB } \\
\text { dengan Fuel Object }\end{array}$ & $\begin{array}{c}\text { Akses Menuju } \\
\text { Fuel Object }\end{array}$ & $\begin{array}{c}\text { Weight } \\
\text { Score }\end{array}$ \\
\hline Prioritas Operasi & 1 & $1 / 2$ & 6 & 6 & 0,370 \\
Fuel remaining day & 2 & 1 & 6 & 4 & 0,478 \\
Jarak SPOB dengan fuel object & $1 / 6$ & $1 / 6$ & 1 & 1 & 0,071 \\
Akses menuju fuel object & $1 / 6$ & $1 / 4$ & 1 & 1 & 0,081 \\
\hline
\end{tabular}

\subsection{Struktur Hierarki}

Penyusunan struktur hierarki dilakukan untuk mempermudah proses pengambilan keputusan. Sebelum melakukan proses penyusunan struktur hierarki, dilakukan pengumpulan informasi yaitu dengan melakukan wawancara langsung kepada 3 responden yang berkompeten pada bidang tersebut. Berikut pada Gambar 4 disajikan struktur hierarki AHP.

Struktur hierarki penjadwalan distribusi BBM menggunakan SPOB terdiri dari 4 tingkatan. Pada tingkat pertama (level 1) adalah puncak hierarki yang merupakan tujuan dari sistem yang akan diselesaikan yaitu berupa penentuan prioritas fuel object mana yang akan diisi BBM terlebih dahulu oleh SPOB. Pada tingkat kedua (level 2), terdiri dari kriteria utama yang mempengaruhi secara langsung tujuan atau penentuan keputusan yang akan diambil oleh decision maker. Kriteria utama tersebut terdiri dari 4 bagian, yaitu prioritas operasi, fuel remaining day fuel object, jarak SPOB dengan fuel object, dan akses menuju fuel object. Pada tingkat ketiga (level 3), yaitu berupa kriteria yang berhubungan langsung dengan fuel object. Terdiri dari 6 subkriteria prioritas operasi, 5 subkriteria fuel remaining day fuel object, 5 subkriteria jarak SPOB dengan fuel object dan 3 subkriteria akses menuju fuel object. Pada tingkat keempat (level 4) yaitu fuel object yang merupakan satu set alternatif dari penjadwalan distribusi BBM menggunakan SPOB. Masing-masing fuel object ini nantinya akan dinilai berdasarkan kriteria pada level 4, dan selanjutnya hasil penilaian tersebut akan dijadikan dasar penentuan penjadwalan distribusi BBM.

\subsection{Perhitungan Bobot}

Perbandingan berpasangan (pairwaise comparison) digunakan pada kuesioner untuk mengetahui nilai tingkat kepentingan dari kriteria dan subkriteria. Selanjtunya hasil pengisian kuesioner akan diolah untuk mendapatkan nilai bobot. Proses pembobotan dilakukan dengan metode exact method (eigenvector). Berdasarkan hasil kuesioner yang dijawab oleh 3 responden untuk tingkat 2 (kriteria) maka diperoleh nilai rata-rata seperti pada Tabel 1 diperoleh nilai rata-rata untuk tingkat 2 (kriteria).

Dari nilai rata-rata tersebut, maka diperoleh sebuah matriks berpasangan $(4 \mathrm{x} 4)$ yang digunakan untuk menghitung bobot, sehingga diperoleh nilai $\lambda=$ 4,118 . Selanjutnya indeks konsistensi dapat dihitung.

$$
C I=\frac{4,118-4}{3}=0,039
$$

Nilai $C I$ diubah ke bentuk rasio konsistensi $(C R)$

$$
C R=\frac{0,039}{0,9}=0,043
$$

Nilai $\mathrm{CR} \leq 0,1$ maka matriks perbandingan untuk struktur hierarki level 2 sudah memenuhi persyaratan konsistensi.

Selanjutnya dilakukan perhitungan nilai rata-rata dari kuesioner untuk tingkat 3 (subkriteria) dari masingmasing kriteria.

- Kode A : Special Request

- Kode B : Site Shore Tank

- Kode C : Rig Pengeboran

- Kode D : Barge/ Kapal intervensi sumur

- Kode E : Crane Barge Konstruksi

- Kode F : Kapal LCT dan Tug Boat lainnya

- Kode G : Kurang dari 1 hari

- Kode H : 1 hari

- Kode I : 2 hari

- Kode J : 3 hari

- Kode K : Lebih dari 3 hari

- Kode L : $<8$ nautical miles

- Kode M : 8,01-12 nautical miles

- Kode N : 16,01 - 20 nautical miles

- Kode O : 16,01 - 20 nautical miles

- Kode P : > 20 nautical miles

- Kode Q : Perlu air pasang sangat tinggi. Jika SPOB mengisi fuel object, SPOB baru bisa keluar di air pasang hari berikutnya

- Kode R : Perlu air pasang sedang. Jika SPOB mengisi fuel object, SPOB baru bisa keluar di air pasang berikutnya ( \pm 12 jam $)$

- Kode S : Akses ke fuel object bebas setiap saat

\subsection{Perhitungan Nilai Akhir}

Setelah melakukan perhitungan bobot untuk masing-masing kriteria dan subkriteria, maka langkah berikutnya adalah mengubah bobot (weight score) subkriteria tersebut dalam bentuk ideal (ideal form). Nilai ideal form diperoleh dari hasil pembagian setiap nilai subkriteria dengan nilai tertinggi diantara subkriteria (dalam satu kriteria yang sama). Nilai bobot subkriteria dalam bentuk ideal form ditampilkan pada Tabel 2.

Berdasarkan Tabel 2 dapat dilihat bahwa fuel remaining day merupakan prioritas tertinggi dengan bobot 0,478, disusul oleh prioritas operasi, akses dan jarak. Sedangkan bobot masing-masing subkriteria sudah berubah dalam bentuk ideal form agar sistem berada dalam kondisi open system, sehingga memungkinkan untuk menambah dan mengurangi alternatif secara langsung. 
Tabel 2. Nilai Bobot Subkriteria Dalam Ideal Form

\begin{tabular}{|c|c|c|c|c|}
\hline & & Bobot & & Bobot \\
\hline \multirow{19}{*}{$\begin{array}{l}\text { Prioritas } \\
\text { pengisian } \\
\text { fuel object }\end{array}$} & \multirow{6}{*}{$\begin{array}{l}\text { Prioritas } \\
\text { operasi }\end{array}$} & \multirow{6}{*}{0,370} & Rig pengeboran & 1 \\
\hline & & & Site shore tank & 0,543 \\
\hline & & & Barge/ kapal intervensi sumur & 0,400 \\
\hline & & & Crane barge konstruksi & 0,307 \\
\hline & & & Special request & 0,126 \\
\hline & & & Kapal LCT dan Tug boat lainnya & 0,091 \\
\hline & \multirow{5}{*}{$\begin{array}{c}\text { Fuel } \\
\text { remaining } \\
\text { day fuel } \\
\text { object }\end{array}$} & \multirow{5}{*}{0,478} & Kurang dari 1 hari & 1 \\
\hline & & & 1 hari & 0,729 \\
\hline & & & 2 hari & 0,345 \\
\hline & & & 3 hari & 0,159 \\
\hline & & & Lebih dari 3 hari & 0,074 \\
\hline & \multirow{5}{*}{$\begin{array}{c}\text { Jarak } \\
\text { SPOB } \\
\text { dengan fuel } \\
\text { object }\end{array}$} & \multirow{5}{*}{0,071} & $<8$ nautical miles $(<2$ jam perjalanan $\mathrm{SPOB})$ & 1 \\
\hline & & & 8.01-12.0 nautical miles (2-3 jam perjalanan SPOB) & 0,498 \\
\hline & & & 12.01-16.0 nautical miles (3-4 jam perjalanan SPOB) & 0,306 \\
\hline & & & 16.01-20.0 nautical miles (4-5 jam perjalanan SPOB) & 0,177 \\
\hline & & & $>20$ nautical miles $(>5$ jam perjalanan SPOB) & 0,104 \\
\hline & \multirow{3}{*}{$\begin{array}{c}\text { Akses } \\
\text { menuju } \\
\text { fuel object }\end{array}$} & \multirow{3}{*}{0,081} & Akses ke fuel object bebas setiap saat & 1 \\
\hline & & & $\begin{array}{l}\text { Perlu air pasang sedang. Jika SPOB mengisi fuel object, SPOB baru } \\
\text { bisa keluar di air pasang berikutnya ( } \pm 12 \text { jam })\end{array}$ & 0,258 \\
\hline & & & $\begin{array}{l}\text { Perlu air pasang tinggi. Jika SPOB mengisi fuel object, SPOB baru } \\
\text { bisa keluar di air pasang hari berikutnya }\end{array}$ & 0,111 \\
\hline
\end{tabular}

\subsection{Simulasi Penjadwalan dengan AHP}

Setelah mendapatkan bobot dari masing-masing kriteria pada level 2 dan bobot dalam bentuk ideal untuk subkriteria level 3 pada rating approach AHP, maka langkah selanjutnya adalah menentukan perankingan pada alternatif (fuel object) untuk masing masing klaster dengan cara mengevaluasi setiap fuel object didasarkan pada subkriteria yang telah menggunakan bobot ideal. Agar lebih mudah dipahami berikut disajikan algoritmanya.

Klaster 1:

Pada klaster pertama hanya 46 fuel object saja yang berstatus on hire. Lokasi terakhir SPOB 1 berada pada titik lokasi $\alpha 2$. Berdasarkan hasil simulasi, pada jadwal pertama SPOB 1 akan mengisi FO-CCB-10 yang juga berada di lokasi $\alpha 2$. Kemudian FO-SST-04 yang berada pada lokasi $\alpha 1$ dan terakhir adalah FO-LCTB-01 yang berada di lokasi $\alpha 2$. Dari urutan tersebut terlihat bahwa rute SPOB 1 adala titik $\alpha 2 \rightarrow \alpha 1 \rightarrow \alpha 2$. Hasil simulasi terlihat tidak efektif, hal ini terjadi karena bobot untuk jarak 0 sampai dengan 2,5 nautical miles dianggap sama. Akan tetapi dalam kasus ini departemen fuel management bisa mengatur untuk mengisi fuel object pada lokasi $\alpha 2$ dahulu baru menuju lokasi $\alpha 1$. Karena dapat dilihat bahwa dari hasil simulasi pertama, FO-LCTB-01 merupakan nomor urut ketiga, akan tetapi karena SPOB 1 berpindah lokasi ke $\alpha 1$, maka ketika dijalankan simulasi kedua, hasilnya menujukkan bahwa FO-LCTB-01 juga merupakan prioritas selanjutnya yang harus diisi. Artinya jika urutan pengisian kedua dan ketiga diubah maka tidak berpengaruh. Di samping itu selisih bobot masing-masing fuel object ranking pertama sampai dengan ketiga juga tidak jauh berbeda. Untuk urutan 4 dan 5 adalah FO-DR-01 dan FO-DR-02.

\section{- Klaster 2:}

Pada klaster kedua hanya 20 fuel object saja yang berstatus on hire. Lokasi terakhir SPOB 2 berada pada titik lokasi $\beta 4$. Berdasarkan hasil simulasi, pada jadwal pertama SPOB 2 akan mengisi FO-CCB-11 yang juga berada di lokasi $\beta 4$. Kemudian FO-SST-08 dan FOCCB-05 yang sama-sama berada pada lokasi $\beta 9$ dan terkahir FO-CCB-08 yang berada pada titik lokasi $\beta 10$.

\section{- Klaster 3:}

Klaster kedua terdiri dari 23 fuel object dan lokasi terakhir SPOB 3 berada pada titik lokasi $\gamma 8$. Berdasarkan hasil simulasi, pada jadwal pertama SPOB 3 akan mengisi FO-SST-01 yang berada di lokasi $\gamma 1$. Kemudian FO-CCB-03 yang berada di lokasi $\gamma 1$ dan yang terakhir adalah FO-CCB-02 yang berada pada titik lokasi $\gamma 2$.

\subsection{Perbandingan Penjadwalan Hasil Simulasi dengan dan Pelaksanaan Di Lapangan}

Setelah mendapatkan penjadwalan dari hasil simulasi, maka akan dibandingkan dengan jadwal yang telah disusun oleh pihak coordinator

\subsection{Perbandingan Penjadwalan Hasil Simulasi dengan dan Pelaksanaan Di Lapangan}

Setelah mendapatkan penjadwalan dari hasil simulasi, maka akan dibandingkan dengan jadwal yang telah disusun oleh pihak koordinator. Jika dibandingkan hasil simulasi dengan penjadwalan oleh koordinator untuk 5 fuel object pada klaster 1. Terlihat bahwa urutan pertama jadwal koordinator adalah FO-SST-04, sedangkan pada simulasi adalah FO-CCB-10. Hal ini 
mungkin terjadi karena pihak koordinator menganggap FO-SST-04 merupakan jenis site shore tank yang lebih prioritas untuk diisi dibandingkan dengan FO-CCB-10 yang merupakan jenis crane barge konstruksi. Akan tetapi jika dilihat juga kriteria yang lain, ternyata fuel remaining day FO-CCB-10 bernilai -82 hari sedangkan FO-SST-04 adalah 1 hari, serta jarak lokasi SPOB 1 lebih dekat dengan lokasi FO-CCB-10. Artinya secara evaluasi nilai berdasarkan kriteria yang ada, FO-CCB10 lebih prioritas untuk diisi. Urutan kedua jadwal koordinator adalah FO-LCTB-02. Tentu saja koordinator memiliki alasan mengapa memilih FOLCTB-02, walaupun sebenarnya jarak antara last position SPOB $1(\alpha 1)$ dan FO-LCTB-02 $(\gamma 1)$ cukup jauh yaitu 42,6 nautical miles. Ternyata berdasarkan update data lokasi, FO-LCTB-02 akan bergerak dari titik $\gamma 1$ menuju titik lokasi $\alpha 2$. Akhirnya dari perspektif koordinator akan menjadi lebih efektif untuk mengisi juga FO-LCTB-02 yang akan sama-sama berada di titik lokasi pengisian urutan ketiga (FO-WIB-01). Padahal jika FO-LCTB-02 dievaluasi berdasarkan kriteria prioritas operasi termasuk kedalam jenis kapal LCT dan tug boat lainnya, dan dari kriteria fuel remaining day juga hanya 2 hari. Artinya apabila dinilai, sebenarnya FO-LCTB-02 tidak termasuk kedalam prioritas untuk diisi. Untuk urutan ketiga adalah FO-WIB-01, dalam evaluasi nilai kriteria prioritas operasi termasuk kedalam jenis kapal intervensi sumur dan fuel remaining daynya adalah 2 hari. Artinya jika dinilai juga dengan kriteria yang ada, ternyata juga bukan termasuk prioritas. Akan tetapi jika dilihat ternyata FOWIB-01 berada di lokasi yang sama dengan urutan pengisian berikutnya. Secara umum tanpa memperhatikan urutan, hanya terdapat 2 fuel object saja yang sama antara hasil simulasi dengan jadwal yang dibuat oleh koodinator.

Pada klaster 2, terlihat jadwal pengisian hanya berbeda pada urutannya saja, sedangkan 4 fuel object yang terpillih adalah sama. Berdasarkan hasil simulasi urutan pertama adalah FO-CCB-111 lokasi $\beta 4$, kemudian FO-SST-08 dan FO-CCB-05 di lokasi $\beta$, dan FO-CCB-08 di lokasi $\beta 10$. Jika dibandingkan dengan urutan lokasi jadwal koordinator pada tabel 6, maka urutan dari jadwal lokasi hasil simulasi akan terlihat lebih efektif. Selanjutnya pada klaster 3 terlihat jadwal hasil simulasi dan koordinator memiliki urutan yang sama persis yaitu FO-SST-01 dan FO-CCB-03.

\section{Kesimpulan}

Berdasarkan hasil perhitungan bobot dengan AHP, maka dasar pertimbangan yang dapat digunakan untuk pengambilan keputusan dalam penjadwalan pengisian BBM pada fuel object di area kerja industri ekspolorasi minyak bumi yaitu kriteria fuel remaining day fuel object dengan bobot 0,478 ; prioritas operasi dengan bobot 0,370 ; akses menuju fuel object dengan bobot 0,081 ; dan kriteria jarak SPOB dengan fuel object dengan bobot 0,071. Adapun subkriteria intensitas rating pada masing masing leaf kriteria dalam bentuk bobot ideal form digunakan untuk mengevaluasi nilai dari masing masing fuel object. Pengembangan sistem pengambilan keputusan berbasis Rating approach AHP bisa digunakan sebagai tools yang sangat baik dalam penentuan ranking fuel object sebagai dasar pertimbangan untuk mendapatkan sebuah sistem penjadwalan pengisian BBM yang terukur dan dapat dipertanggungjawabkan. Perbandingan hasil antara simulasi dan jadwal yang dibuat oleh koordinator hanya terdapat sedikit perbedaan saja terutama untuk klaster 1 . Akan tetapi terlihat bahwa penggunaan sistem penjadwalan dengan metode rating approach AHP dinilai lebih konsisten karena hasil penjadwalannya didasarkan pada evaluasi nilai dengan bobot yang sudah ditentukan dan disepakati bersama, sehingga alasan pemilihan urutan pengisian akan menjadi transparan dan jelas, serta dapat meminimalisir perbedaan penjadwalan antar koordinator karena perbedaan subjektivitas.

\section{Daftar Pustaka}

Arditiya, Maulita, Rahmat, \& Qudsia, T.A., (2020). Implementasi K3LL (Keselamatan Dan Kesehatan Kerja Serta Lindung Lingkungan) dalam Proses Bunker Kapal SPOB di PT Cindara Pratama Lines Balikpapan. Jurnal Maritim, 10(2), 50-58.

Dočkalíková, I., and Kashi, K. (2013). Employees`Recruitment: Selecting The Best Candidates by The Utilization of AHP and WSA Method. International Days of Statistics and Economics, 347-356.

Guritno, S., dan Triwibowo, P. (2018). Upaya Meningkatkan Peran Dynamic Positioning Operator (DPO) dalam Mengoperasikan Kapal OSV dengan Dynamic Positioning System. Jurnal Saintek Maritim, Vol. 17 (2), 1-14.

Gusmery, I., dan Rachman, A. (2013). Optimasi Rute dan Jadwal Pelayanan Pengisian BBM MFO 380 bagi Kapal-Kapal Tujuan Luar Negeri untuk Wilayah Kaltim dan Kalsel. Depok: Universitas Indonesia.

Http://maps.google.com/, diakses pada tanggal 6 November 2020 pukul 13:00 WIB.

Ilhami, R.S., dan Rimantho, D. (2017). Penilaian Kinerja Karyawan dengan Metode AHP dan Rating Scale. Jurnal Optimasi Sistem Industri, 16(2), 150-157.

Mujito., Prasetyo, B. H., Subandi., Anubhakti, D., dan Widjaja, A. (2018). Selection of Prospective Employees Using Analytical Hierarchy Process (AHP) and ISO 9126. International Conference on Applied Information Technology and Innovation (ICAITI), 41-45.

Norddin, N. I., Ahmad, N., dan Yusof, Z. M. (2015). Selecting Best Employee of the Year Using Analytical Hierarchy Process. Journal of Basic and Applied Scientific Research, 5(11),72-76.

Rodrigues, V.P., Morabito, R., Yamashita, D., da Silva, B., \& Ribas, P. (2016). Ship Routing with Pickup and Delivery for a Maritime Oil Transportation 
System: MIP Model and Heuristics. Systems, 4(3), 31.

Saaty, T. L. (1980). The Analytic Hierarchy Process. McGraw-Hill, New York.

Sinharay, S. (2010). An Overview of Statistics in Education. International Encyclopedia of Education. Amsterdam: Elsevier Ltd.

Tseng, P., and Cullinane, K. (2018). Key criteria influencing the choice of Arctic shipping: a fuzzy analytic hierarchy process model. Maritime Policy \& Management, 45(4), 422-438. Usman, H., dan Sobari, N. (2013). Aplikasi Teknik Multivariate Untuk Riset Pemasaran. Jakarta: Raja Grafindo Persana.

Yuliani, I. D. A. E. (2013). Sistem Pendukung Keputusan Pemilihan Karyawan Terbaik Dengan Metode Analytical Hierarchy Process. Sisfotenika, 3(2), 105-114. 